Revista Iberoamericana, Vol. LXXIII, Núm. 221, Octubre-Diciembre 2007, 827-842

\title{
POESÍA SIN HILOS: \\ RADIO Y VANGUARDIA
}

POR

RubÉn Gallo

Princeton University

Durante las primeras décadas del siglo xx, los poetas de vanguardia de todo el mundo celebraron la invención de la radio (o el "teléfono sin hilos" como se la conocía en esos años) no solamente como una nueva y moderna tecnología, sino también como la inspiración para una nueva poesía. En sus manifiestos el futurista italiano F. T. Marinetti celebró la "imaginación sin hilos”, un tipo de escritura que prometía liberar a la poesía de la sintaxis y la puntuación -los "hilos” que mantenían a la escritura atada a una época pretecnológica- e incitó a los poetas jóvenes a buscar nuevos modelos literarios en la radio. Los críticos Gregory Whitehead y Douglas Kahn han explorado la fascinación que la radio ejerció sobre las distintas vanguardias en su antología The Wireless Imagination [La imaginación sin hilos], un volumen que examina la relación entre los escritores y la radiodifusión en Inglaterra, Francia y Alemania. En este ensayo examinaré la influencia del discurso radiofónico en los poetas españoles y latinoamericanos de las primeras décadas del siglo xx. Presentaré el caso de un grupo de poetas -los estridentistas mexicanos-como un ejemplo paradigmático de cómo la nueva tecnología dio origen a una nueva poesía. La poesía de los estridentistas es uno de los mejores ejemplos de la “imaginación sin hilos” anhelada por Marinetti.

La época moderna se caracterizó por una serie de revoluciones tecnológicas: la cámara transformó nuestra manera de ver el mundo, la máquina de escribir mecanizó la escritura y la radio electrificó el oído al transformar el sonido en una serie de impulsos electromagnéticos. Cuando los primeros radioescuchas se sentaron frente a un aparato receptor y percibieron la voz de los primeros locutores, seguramente tuvieron la extrañísima sensación de estar oyendo lo que aparentaba ser una voz humana pero que en realidad no era más que el resultado de una serie de operaciones eléctricas. La radio fue un medio más misterioso que la fotografía o la escritura mecánica por varias razones: este nuevo medio transmitía voces descorporizadas desde un origen desconocido y tenía el poder de enviar mensajes sin hilos, como por arte de magia, de un país a otro y de un continente a otro. Esta nueva tecnología transformaba a los radioescuchas en ciegos -al menos durante los minutos que duraba la audición- y los obligaba a reconstruir los otros sentidos basándose exclusivamente en los sonidos emitidos por el receptor. Y el medio de la radiofonía era totalmente invisible: las ondas imperceptibles que transportaban sonidos y música entre países y continentes. Además, un receptor de radio era un aparato infinitamente más 
complejo que una cámara o una máquina de escribir: cualquier persona podía aprender a tomar fotografías o a mecanografiar, pero la operación de un aparato de radio estaba reservada a los expertos en la doctrina hertziana.

Marinetti publicó su primer “Manifiesto del futurismo” en 1909. En los próximos años, varios poetas españoles y latinoamericanos siguieron el llamado de Marinetti y experimentaron con maneras de inventar una nueva poesía inspirada en la radiofonía. Uno de los primeros fue el chileno Vicente Huidobro, que en 1918 publicó “Tour Eiffel”, una plaquette escrita en francés e ilustrada por el pintor simultaneísta Robert Delaunay. Este poema es un canto a la Torre Eiffel, una estructura que además de ser un imponente monumento a la modernidad funciona también como antena de radio. ${ }^{1}$ En su poema, Huidobro intenta visualizar -a través de imágenes sinestésicas- las ondas cargadas de voces y sonidos que emanan de la antena:

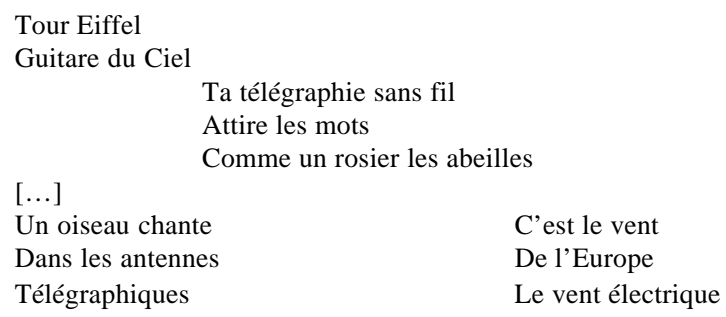

La difusión de las ondas es un fenómeno puramente acústico. Para visualizarlo, Huidobro "traduce” los sonidos en imágenes visuales: la torre atrae los sonidos "como un rosal las abejas”. Y como Marinetti, el poeta chileno celebra la radiodifusión como un triunfo de la modernidad europea: "Es el viento / de Europa / el viento eléctrico".

Uno año más tarde, el ultraísta español Juan Larrea Celayeta le dedicó un poema entero a las maravillas de la radiodifusión: el “Nocturno TSH” de 1919. El título incluye las siglas de "Telefonía Sin Hilos”, el nombre que por esos años se le daba a la radio. El poema incluye estos versos:

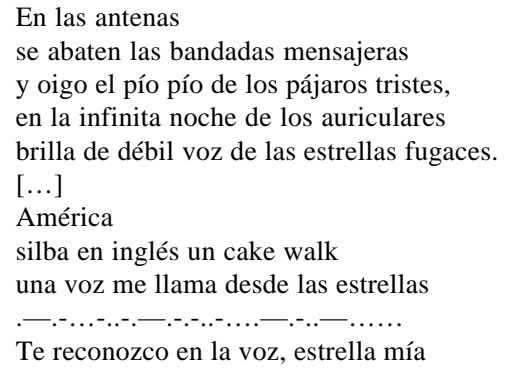

${ }^{1}$ La Torre Eiffel fue uno de los temas privilegiados en la pintura de Delaunay. Este artista realizó varios dibujos y grabados de la torre para ilustrar los versos de Blaise Cendrars. 


$$
\begin{aligned}
& \text { [...] } \\
& \text { En los aires } \\
& \text { las palomas se enredan las alas } \\
& \text { en los invisibles cables. (209) }
\end{aligned}
$$

El poeta dibuja un cielo oscuro, lleno de ondas que transportan todo tipo de sonidos invisibles: música (“un cake walk” en inglés), palabras (emitidas por la voz que llama desde las estrellas), y también mensajes telegráficos (como vemos en el fragmento de clave Morse insertado en el texto). Este poema también reitera uno de los temas preferidos de Marinetti (y de Huidobro): el deseo de traducir los sonidos radiofónicos en imágenes visuales ("las palomas se enredan las alas / en los invisibles cables"), pero también introduce nuevos temas, como la relación entre la radiodifusión y otro de los productos de la época moderna: la música de jazz (“América / silba en inglés un cake walk”).

También en España, Ramón Gómez de la Serna meditó acerca de los efectos de la radio sobre el cuerpo humano en algunas de sus Greguerías: “Los auriculares son las gafas ahumadas de los oídos / [...] Micrófono: oreja de todos” (102). Las Greguerías fueron publicadas entre 1918 y 1961. No tenemos las fechas de cada una de ellas, pero las imágenes que presenta en estos dos aforismos nos llevan a concluir que fueron escritos en la década de los veinte, cuando la mayoría de los aficionados escuchaban las emisiones radiales usando un par de audífonos.

En 1919 el poeta vanguardista catalán Joan Salvat Papasseit publicó su primer libro de poesía, titulado Poemas en ondes hertzianes. A pesar del título, los poemas contenidos en este libro no incluyen ninguna imagen radiofónica, aunque abundan las referencias a otros inventos de la modernidad: la electricidad, los tranvías y los autobuses. Al llegar la década de los veinte, la radio se había convertido en un tema tan popular que muchos poetas salpicaban sus creaciones -y los títulos de sus libros- de referencias a la radiofonía pero sin desarrollar en detalle la relación entre este medio y la literatura como lo habían hecho los primeros vanguardistas. Encontramos otro ejemplo de esta fetichización de la radio en el poemario del checo Jaroslav Seifert titulado Na vlnach TSF [En las ondas de la TSH, 1925], un libro que, al igual que el volumen de Salvat Papasseit, no contiene ninguna referencia a la radio fuera del título.

En México los poetas de vanguardia tuvieron una intensa fascinación con la radio. Los estridentistas, un grupo de poetas que en 1921 lanzaron un estrepitoso manifiesto que pedía, entre otras cosas, el envío de "Chopin a la silla eléctrica”, celebraron la radio como el gran símbolo de la modernidad. A diferencia de los otros poetas que hemos discutido en este ensayo, los estridentistas también participaron activamente en la radiodifusión. La primera estación de radio en la ciudad de México salió al aire el 8 de mayo de 1923 con un programa que inició con el poeta Manuel Maples Arce leyendo un poema estridentista sobre la radio: “TSH: el poema de la radiofonía”. ${ }^{2}$ Maples Arce ya había publicado un libro

\footnotetext{
${ }^{2}$ Este primer programa también incluyó a Andrés Segovia interpretando piezas de Chopin y de Mozart; a Celia Montalván cantando canciones mexicanas; y a Manuel M. Ponce ejecutando algunas de sus propias composiciones. Varios artículos periodísticos se publicaron sobre este programa: $E l$ Universal (9 de mayo de 1923) y "Un gran triunfo de El Universal Ilustrado y de la 'Casa del Radio”" El Universal Ilustrado 313 (10 de mayo de 1923).
} 
de poemas inspirados en la radiofonía (Andamios interiores: poemas radiográficos) y en este nuevo texto aparece, de nuevo, la imagen de un cielo lleno de ondas invisibles, llenas de voces y música:

TSH $[\ldots]$

¿En dónde estará el nido

de esta canción mecánica?

[...]

Manicomio de Hertz, de Marconi, de Edison!

El cerebro fonético baraja

la perspectiva accidental

de los idiomas.

Hallo!

$$
\begin{aligned}
& \text { Una estrella de oro } \\
& \text { ha caído en el mar. (“TSH”) }
\end{aligned}
$$

Este poema introduce una estrategia que no habíamos visto en los poemas de Huidobro o Larrea Celayeta: la incorporación de términos técnicos de la radiofonía como “audión inverso", uno de los componentes de los primeros receptores. El 18 de mayo de 1923 El Universal Ilustrado había publicado un artículo sobre la obsesión que estaba extendiéndose por todo México (y por todo el mundo) y que el autor llamó "La locura del radio". Maples Arce se refiere a esta "locura” en su poema, en los versos que relacionan la radiodifusión con el "manicomio de Hertz, de Marconi, de Edison”. La radio es un invento “loco”, que surge de los descubrimientos de estos tres inventores. Pero, ¿por qué se asocia a la radio con la locura? Porque este invento llenó los cielos de música extraña (los “cake walks" de Larrea Celayeta) y de palabras en lenguas incomprensibles (como el "Hallo" anglo-germánico que aparece en el poema de Maples Arce); una serie de comunicaciones que gran parte del público consideró como incomprensibles, irracionales y desquiciadas.

Irónicamente, Maples Arce aseguró -en una entrevista realizada en los años setentano haber conocido los poemas radiofónicos que se habían escrito antes de su "TSH":

No creo que haya en la literatura [...] un poema anterior a éste que se ocupara de la radiofonía. Insisto en ello: no creo que exista. En la literatura europea de vanguardia de entonces, cierto, se habían introducido expresiones, palabras y giros de la vida moderna; pero poemas que reflejaran un poco el ambiente de inquietud e interés suscitado por la radiofonía [...], nadie los había escrito. (Gálvez 733)

Maples Arce, parece ser, ignoraba los poemas de Marinetti, de Huidobro, de Larrea Celayeta.

Incluso antes de que se inaugurara la primera estación radiodifusora en la ciudad de México, muchos escritores mexicanos ya habían celebrado esta nueva tecnología en sus textos. Un mes antes de la primera emisión radial, El Universal Ilustrado le dedicó un número entero a la radio: allí se publicó por primera vez el poema “TSH” de Maples Arce (acompañado de un grabado futurista realizado por Fernando Bolaños Cacho), así como 
un ensayo de Arqueles Vela titulado "El hombre antena” (sobre uno de los técnicos que trabajaban en la estación de radio), y otros textos raros, como "La radiofonía y el amor" de Pepe Rouletabille. “El hombre Antena”, escribe Arqueles Vela, “es como un pararrayos de los crímenes, los Jazz Bands, las audiciones que se reparten diariamente a las estaciones. El Hombre Antena vive más que ninguno ese cosmopolitanismo moderno de las ciudades”.

Maples Arce y los otros poetas estridentistas tuvieron tal pasión por esta nueva tecnología que la radio pasó a ser una de las obsesiones más famosas del movimiento. Carlos Noriega Hope, el editor de El Universal Ilustrado, llegó a escribir que "El estridentismo es hermano de leche de la Radiofonía. ¡Son cosas de vanguardia!” (11). Y tenía razón: hay un gran número de paralelos entre las historias del estridentismo y de la radiodifusión en México. El movimiento estridentista se inicia en 1921, el mismo año en que comienzan las pruebas de radiodifusión en la ciudad de México. Los miembros del movimiento vanguardista participaron, desde sus inicios, en las primeras estaciones difusoras de la capital. Además, tanto la radio como el movimiento estridentista estaban enfocados en el presente: en su primer manifiesto, Maples Arce anuncia: "Nada de futurismo [...] Hagamos actualismo. Ya Walter Bonard Arensberg lo exaltó en una estridencia afirmativa al asegurar que sus poemas sólo vivirían seis horas" (citado en Schneider 272). La radiodifusión fue un medio igualmente "presentista”: en Radio, una de las primeras aproximaciones teóricas al medio, Rudolf Arnheim celebra el vínculo privilegiado que establece la radiodifusión con el presente: "that inspiration of the moment which is the special glory of wireless, allowing the listener to participate in events in statu nascendi" (126). El estridentismo y la radio, como podemos ver, son dos productos de la modernización tecnológica que caracterizó al periodo posrevolucionario.

Además de Maples Arce otros miembros del movimiento estridentista escribieron poemas sobre la radio. En 1924 Luis Quintanilla publicó un poemario titulado Radio: poema inalámbrico en trece mensajes. A diferencia de los libros de Salvat Papasseit y Seifert, que, como vimos, sólo se referían a la radio en el título, el poemario de Quintanilla es uno de los experimentos más interesantes sobre la relación entre la radio y la poesía. La portada del libro muestra un cielo nocturno lleno de ondas radiales y en el frontispicio encontramos lo que aparenta ser un ideograma en caligrafía japonesa o china. En realidad se trata de las iniciales del autor: Quintanilla adoptó el pseudónimo orientalista de "Kyn Taniya” y aquí encontramos la "K” de "Kyn” colocada horizontalmente sobre la "T” de “Taniya”. Esta extraña construcción alfabética es también una antena de radio: el autor transformó su propio nombre en un aparato receptor.

Radio contiene varios poemas con referencias radiofónicas. "Midnight frolic" elabora uno de los temas que ya hemos visto en los poemas de Larrea Celayeta y Maples Arce: un cielo nocturno lleno de ondas invisibles que transportan música y voces de un extremo a otro del mundo.

Silencio

Escuchad la conversación de las palabras

en la atmósfera 


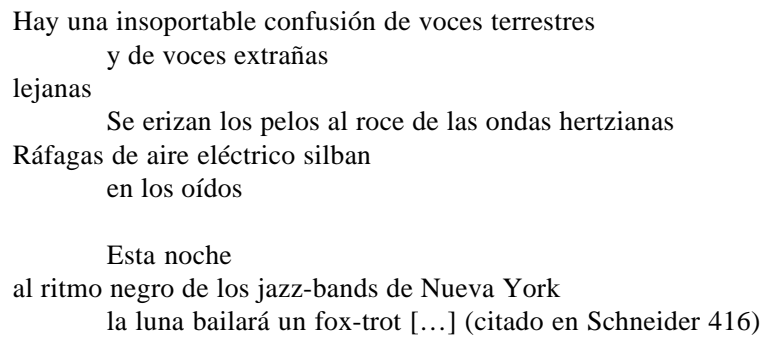

Al igual que Larrea Celayeta, Quintanilla relaciona el radio con la música de jazz, otro invento de la época moderna. ${ }^{3} \mathrm{Y}$ al igual que los otros poetas que hemos analizado, Quintanilla busca imágenes poéticas que nos permitan visualizar las ondas invisibles: en este caso la carga eléctrica de las ondas produce una reacción muy visible en el cuerpo del radioescucha: "se erizan los pelos al roce de las ondas hertzianas".

"Alba”, otro de los poemas recogidos en Radio, evoca la presencia de un nuevo elemento -las antenas radiofónicas- en el paisaje urbano: "[...] y las frívolas antenas / gozan eléctricos espasmos de frescura”. Pero el poema más original de todo el libro es "IU IIIUUU IU”, un texto con un título onomatopéyico que imita los silbidos que emite un receptor de radio durante el proceso de sintonía. El poema consiste en una serie de fragmentos de emisiones de radio y nos da una muy buena idea del tipo de programas que se transmitían en 1924.

Después de este breve recorrido a través de la poesía radiofónica en España y América Latina, quisiera analizar el caso especial de los estridentistas en más detalle. La participación directa de estos poetas en la radiodifusión mexicana sugiere una serie de preguntas: ¿qué diferencias hay entre los escritos estridentistas sobre la radio y aquellos de otros poetas como Huidobro o Larrea Celayeta que no participaron directamente en la radiodifusión? ¿Cuál es la relación entre el estridentismo y los otros movimientos de vanguardia que hemos mencionado en este artículo? ¿Qué relación hay entre los escritos radiofónicos de los estridentistas y sus teorías sobre el lenguaje y la poesía?

Como ya hemos visto, los estridentistas participaron en la radiodifusión de una manera más directa que los otros poetas vanguardistas. Muchos poetas -incluyendo a Gómez de la Serna y a Salvat Papasseit- solamente incluyeron referencias dispersas a la radio en sus obras. No desarrollaron una meditación profunda sobre la relación entre este nuevo medio y la literatura, sino que simplemente usaron la palabra “radio” como símbolo

\footnotetext{
${ }^{3}$ Los estridentistas escribieron varios textos sobre la música de jazz como símbolo de la modernidad. Uno de los más interesantes es el ensayo de Maples Arce que lleva el título "JAZZ =لVTRS" y que se publicó en El Universal Ilustrado. Escribe el poeta: "La estructuralización mecánica de las grandes ciudades modernas, en su expresión auditiva (el ruido de los motores, el silbato de las sirenas, la trepidación de las máquinas y todas las manifestaciones fonéticas Brrs ttrns!!! Trff tRRReSSNNN bbbRRr Ruuuuu!! de los automóviles, trasatlánticos, aeroplanos, etc. considerados como elementos arquitecturales del jazz, poema neo-musical, debe sólo recordarse en su valor sugerido y no real”.
} 
de modernidad, como una referencia más a la nueva era que había producido automóviles, tranvías, gramófonos y tantas otras máquinas.

Durante la década de los veintes muchos poetas jóvenes siguieron una estrategia parecida y escribieron poemas que mencionaban la radio, la electricidad u otras tecnologías pero sin analizar la manera en que estos nuevos inventos podían influir sobre la poesía. Esta tendencia se generalizó a tal grado que César Vallejo la criticó fuertemente en un artículo. Según Vallejo, los poetas debían reflexionar sobre la relación entre la poesía y los nuevos inventos y no simplemente nombrarlos en sus composiciones:

\footnotetext{
Poesía nueva ha dado en llamarse a los versos cuyo léxico está formado de las palabras «[...] radio, jazz band, telegrafía sin hilos», y en general, de todas las voces de las ciencias e industrias contemporáneas, no importa que el léxico corresponda o no a una sensibilidad auténticamente nueva. Lo importante son las palabras.

Pero no hay que olvidar que esto no es poesía nueva ni antigua, ni nada. Los materiales artísticos que ofrece la vida moderna han de ser asimilados por el espíritu y convertidos en sensibilidad. El telégrafo sin hilos, por ejemplo, está destinado, más que a hacernos decir «telégrafo sin hilos» a despertar nuevos temples nerviosos, profundas perspicacias sentimentales, amplificando vivencias y comprensiones y densificando el amor; la inquietud entonces crece y se exaspera y el soplo de la vida se aviva. Esta es la cultura verdadera que da el progreso; este es su único sentido estético, y no el de llenarnos la boca con palabras flamantes. (citado en Schwartz 45)
}

Según Vallejo hay una gran diferencia entre los poetas que simplemente dicen las palabras "radio" o "teléfono sin hilos" (como Salvat Papasseit) y aquellos que logran "asimilarlas” de una manera más profunda (como Quintanilla).

Los estridentistas fueron los únicos poetas de vanguardia en el mundo hispanoamericano que lograron "asimilar” la radiofonía a la literatura. Pero, ¿qué quiere decir "asimilar" la radio a la literatura? Como hemos visto, los estridentistas no sólo escribieron sobre la radio sino que también participaron en las primeras transmisiones radiofónicas, diseñaron carteles y anuncios para la estación de El Buen Tono e incluso intentaron construir una estación de radio estridentista. ${ }^{4}$ Además, como veremos en la discusión del poema de Quintanilla, los textos estridentistas resaltan los efectos culturales de la radio.

Para examinar la diferencia entre los textos estridentistas y otros escritos sobre la radio nos referiremos a la terminología introducida por André Cœuroy, uno de los primeros teóricos del medio, en su Panorama de la radio (1930). En su libro, Cœuroy introduce dos términos muy útiles para analizar la relación entre literatura y radio. Según el autor, los textos dedicados a este medio pueden ser de dos tipos: "radiofónicos" o "radiogénicos”. Los escritos radiofónicos se limitan a describir la radio y los aspectos de la radiodifusión mientras que los textos radiogénicos -como los radiogramas- están escritos para ser transmitidos al aire. A Cœuroy le interesan los textos radiogénicos porque en ellos todos los elementos -desde la estructura narrativa hasta la duración-están determinados por las posibilidades y las limitaciones del medio (224). Con esta teoría

\footnotetext{
${ }^{4}$ Véase Gallo.
} 
Cœuroy expresa un punto de vista casi idéntico al de Vallejo. Al igual que el poeta peruano, el crítico francés considera la literatura radiogénica -es decir, aquella que logra “asimilar” los efectos del medio- como un ejercicio más complejo y más interesante que el de los escritores que simplemente toman la radio como tema, llenando sus poemas de "palabras flamantes”. La redacción de textos radiogénicos presupone el conocimiento de la radiodifusión, de sus características técnicas y de sus limitaciones.

Antes de los estridentistas, la mayoría de los escritores que se interesaron en la radio produjeron textos radiofónicos: poemas que celebran la nueva tecnología pero que obviamente no fueron escritos para ser leídos al aire. Los estridentistas, en cambio, escribieron el primer poema radiogénico en la literatura mexicana: "TSH” de Manuel Maples Arce. En una entrevista realizada en los años setenta, Maples Arce explica cómo escribió este poema específicamente para su transmisión por radio:

\footnotetext{
Este poema [“TSH”] lo escribí especialmente para la velada de la apertura de la emisora radiofónica que dirigía Carlos Noriega Hope. Unos días antes de la inauguración de esa radiodifusora [...] Noriega Hope me pidió que escribiera un poema sobre la radiofonía.

Yo nunca había oído la radio. Ni siquiera conocía un aparato. Eran esos días en que empezaba el interés por la radiofonía. Y fui a casa de un amigo [...] y oímos una estación, con todos los problemas que se planteaban entonces a los aparatos y $[\ldots]$ bueno, tuve una impresión viva de todos esos ruidos y esas músicas que pasaban de una onda a otra, con cierta confusión. Bajo los efectos de esa audición me fui a casa, ya muy tarde, y escribí TSH. Cuando Noriega Hope lo recibió, me pagó 15 pesos por él. (Gálvez 733)
}

Como podemos ver el poema de Maples Arce es radiofónico y radiogénico a la vez: se trata de un poema sobre la radio -la radiodifusión es el tema del texto-que también fue escrito para ser leído al aire. Se trata de un ejercicio muy original, ya que no todos los textos radiogénicos son también radiofónicos. El resultado es una composición que pone en escena (y en los oídos de los radioescuchas) una de las estrategias privilegiadas de los poetas de vanguardia: la mise en abîme. Cuando leyó “TSH” al aire, Maples Arce estaba describiendo la trayectoria de sus palabras: "las estrellas arrojan sus programas[...] / las antenas insomnes del recuerdo / recogen los mensajes / inalámbricos”. Es un poema que dice lo que hace y hace lo que dice.

$\mathrm{Al}$ igual que Vallejo, al igual que Cœuroy, los estridentistas quisieron inventar una literatura sobre la radio que fuera más allá de la simple descripción. Una de las creaciones más originales del movimiento es el poema "IU IIIUUU IU”, recogido en Radio de Luis Quintanilla.Como mencionamos antes, el poema intenta una trascripción de los fragmentos de programas que un radioescucha podría haber captado en 1924 mientras giraba rápidamente la perilla de sintonía de su aparato. He aquí el texto íntegro del poema:

$$
\text { ...IU IIIUUU IU... }
$$

ÚLTIMOS SUSPIROS DE MARRANOS DEGOLLADOS EN CHICAGO ILLINOIS ESTRUDENDO DE LAS CAÍDAS DEL NIÁGARA EN LA FRONTERA DE CANADÁ KREISLER REISLER D’ANNUNZIO FRANCE 


\begin{abstract}
ETCÉTERA Y LOS JAZZ BANDS DE VIRGINIA Y TENESÍ LA ERUPCIÓN DEL POPOCATÉPETL SOBRE EL VALLE DE AMECAMECA ASÍ COMO LA ENTRADA DE LOS ACORAZADOS INGLESES A LOS DARDANELOS EL GEMIDO NOCTURNO DE LA ESFINGE EGIPCIA LLOYD GEORGE WILSON Y LENIN LOS BRAMIDOS DEL PLESIOSAURIO DIPLODOCUS QUE SE BAÑA TODAS LAS TARDES ENLOS PANTANOS PESTILENTES DE PATAGONIA LAS IMPRECACIONES DE GANDHI EN EL BAGDAD LA CACOFONÍA DE LOS CAMPOS DE BATALLA O DE LAS ASOLEADAS ARENAS DE SEVILLA QUE SE HARTAN DE TRIPAS Y DE SANGRE DE LAS BESTIAS Y DEL HOMBRE BABE RUTH JACK DEMPSEY Y LOS ALARIDOS DOLOROSOS DE LOS VALIENTES JUGADORES DE FÚTBOL QUE SE MATAN A PUNTAPIÉS POR UNA PELOTA
\end{abstract}

Todo esto no cuesta ya más que un dólar Por cien centavos tendréis orejas eléctricas y podréis pescar los sonidos que se mecen

en la hamaca kilométrica de las ondas

$$
\text { ...IU IIIUUU IU... }
$$

Es un gran poema pero... ¿`se trata de un texto radiofónico o radiogénico? El autor no escribió el poema para leerlo al aire y por lo tanto no parece encajar en la definición de literatura radiogénica propuesta por Cœuroy, pero podemos ver que la influencia del medio en el texto va más allá de la simple descripción. En unos cuantos versos este poema condensa algunas de las ideas más importantes sobre la radiofonía que surgieron en las primeras dos décadas del siglo xx. El poema abre con un título onomatopéyico que imita los silbidos emitidos por los primeros aparatos receptores mientras el usuario intentaba sintonizarlos. Sigue una secuencia de los fragmentos de programas de radio que el usuario escucharía al mover la perilla de sintonía de un extremo a otro del cuadrante. El resultado es un texto desarticulado y fragmentado que nos lleva de un continente a otro -aunque siempre en español- a gran velocidad: arranca con los "marranos degollados en Chicago Illinois” antes de transportarnos a las cataratas del Niágara “en la frontera del Canadá” y cruzar el océano hacia la patria germánica de "Kreisler Reisler”, la Italia de D’Annunzio y la Francia de tantos "etcéteras". En un instante el poema nos devuelve al continente americano, en donde escuchamos ecos de "los jazz bands de Virginia y Tenesí" antes de volar a México (representado por el volcán Popocatepetl) y efectuar tres viajes relámpago de ida y vuelta - de los Dardanelos a Egipto, de Rusia a Patagonia, de Bagdad a Sevillay aterrizar, por fin, en la tierra de Babe Ruth y Jack Dempsey.

La carrera intercontinental representada en el poema es una evocación metafórica de uno de los aspectos más celebrados de la radio: la capacidad de enviar mensajes y programas de un continente a otro cruzando las fronteras políticas y los accidentes geográficos. Como escribió Rudolf Arnheim: "Wireless [...] passes all customs officers, needs no cable, penetrates all walls and even in house raids it is very difficult to catch" (232). Los primeros teóricos del medio expresaron una gran fascinación ante el 
cosmopolitismo que prometía la radio: este nuevo invento permitiría a la gente más humilde, en los rincones más aislados del mundo, salir de su aislamiento y transformarse en ciudadanos del mundo en contacto con los programas de las capitales de Europa y los Estados Unidos.

En Radio, Arnheim celebra esta promesa de cosmopolitismo a través de una evocación de la heterogeneidad de la radio -una descripción en prosa que representa el mismo caos de programación que el poema de Quintanilla:

I was sitting by the harbour of a south Italian fishing-village. My table stood on the street in front of the café door. The fishermen [...] were gazing down on the boats which were just bringing home the catch. It was very quiet, but suddenly from behind me there came a spitting and a spluttering, then screams and squeaks and whistles -the wireless was being tuned in. The loudspeaker had been set into the front wall of the café and served to catch customers. What the net was to the fishers the loudspeakers was to the café proprietor. When the screaming had stopped we heard an English announcer speaking. The fishermen turned round and listened, even though they could not understand. The announcer informed us that they were going to broadcast an hour of German folk-songs and he hoped we would enjoy them. And then a typical German male voice choir sang the old songs that every German knows from childhood. In German, from London, in a little Italian place where strangers are almost unknown. And the fishermen, hardly one of whom had been in a big town, let alone abroad, listened motionless. After a while the waiter seemed to think we should have a change, so he got on to an Italian station, and as an hour's gramophone record was on just then, we heard a French chansonette. French, from Rome, in that village! (13-4)

Como podemos ver, Anrheim describe el mismo fenómeno que Quintanilla, aunque el crítico alemán le da un tratamiento textual algo distinto. Arnheim escribe un texto radiofónico tradicional, un relato sobre su experiencia tecnológica en el pueblecillo italiano que tiene como tema la radio y su público. El poema de Quintanilla funciona de manera distinta: aunque también se trata de un poema radiofónico, “IU IIIUUU IU” es más que una simple descripción de una experiencia auditiva: este texto intenta transcribir como si se tratara de una grabación- los sonidos emitidos por un aparato de radio.

El poema de Quinanilla se mueve no sólo entre distintos países y regiones geográficas sino también entre distintos tipos de programas de radio: incluye noticias ("la entrada de los acorazados ingleses a los Dardanelos”), música (“jazz bands en Virginia y Tenesí”), así como informaciones raras ("el plesiosaurio diplodocus que se baña todas las tardes en los pantanos pestilentes de Patagonia”). Reunidos en el poema, estos fragmentos crean un mosaico radial.

El poema es una de las mejores ilustraciones del caos que caracterizó a la radio en sus primeros años. Los críticos más acerbos del medio lo acusaron de ser un medio desordenado en el que la música clásica se veía obligada a compartir la misma frecuencia con las noticias y los anuncios publicitarios. Gracias a la heterogeneidad de la programación, un cuarteto de Schubert podía ser interrumpido por un anuncio de jabón.

Las ondas eran un medio anárquico en donde se mezclaban todo tipo de programas sin ton ni son. Incluso Arnheim, un crítico que siempre expresó su entusiasmo por el 
medio, señaló la desorientación que las emisiones pueden producir en los radioescuchas: "The wireless listener bobs like a cork on the waves, hears one after another an endless succession of totally unconnected things, and so entirely without a breathing space that he does not manage subsequently to ponder and consider what he has heard [...]” (265). Incluso los radioescuchas que no cambiaban compulsivamente de una estación a otra (como el narrador del poema de Quintanilla) se hallaban bombardeados por "una secuencia de cosas sin ninguna relación entre si”, ya que los programas de radio eran potpurrís heterogéneos que combinaban lecturas de poesía con música de baile, óperas wagnerianas y anuncios de pasta dental.

Uno de los críticos más feroces del medio fue Georges Duhamel, un pensador mencionado por Walter Benjamin en su célebre ensayo sobre "La obra de arte en la época de su reproducción mecánica” como uno de los representantes de la posición antitecnológica. Duhamel es el autor de Defensa de las letras (1932), una diatriba en contra de la perniciosa influencia del cine y la radio. En este ensayo Duhamel escribe lo siguiente sobre la heterogeneidad del medio:

The real radio lovers, those simple people who really need education, are beginning to prefer noise to books [...] they absorb everything pell-mell: Wagner, jazz, politics, advertising, the time signal, music hall, and the howling of secondary waves [...] We are in utter confusion [...] today the man in the street is fed, morally as well as physically, on a mass of debris which has no resemblance to a nourishing diet. There is no method in this madness, which is the very negation of culture. $(30 ; 35)$

En esta diatriba Duhamel critica el mismo revoltijo acústico que Quintanilla celebra en su poema. Desde este punto de vista antirradial, "IU IIIUUU IU” es un ejemplo de la “acumulación de escombros” en la que se mezcla "el jazz, la política, la publicidad [...] el music hall y el aullido de las ondas secundarias”. A Duhamel le causa horror. A Quinanilla le divierte: “ese aullido de las ondas secundarias” es la mejor descripción del título del poema "IU IIIUUU IU”.

Otros críticos, sin duda dotados de más sentido del humor que Duhamel, celebraron el carácter anárquico y heterogéneo del medio. En 1924 el poeta mexicano Salvador Novo impartió una "Radioconferencia sobre el radio" en la que celebra precisamente la falta de coherencia en la programación. Hablando al aire, Novo interpeló a su público con las siguientes palabras radiogénicas:

Acabáis de escuchar el sexteto All Nuts Jazz Band y ahora oís mis palabras; dentro de diez minutos oiréis Il Bacio [sic], de Arditi, o Guadalupe la Chinaca, de Nervo, o Manon, de Massenet, y podéis estar en la postura que mejor os plazca, con el traje de acostaros, con pantuflas, cosa que no solía hacerse en la ópera, fumando vuestra segunda pipa o dormitando... (24)

A Novo le divierte el revoltijo de las ondas y la yuxtaposición de autores y músicas incompatibles, como por ejemplo Amado Nervo -uno de los poetas más cursis de la literatura mexicana- acompañado por la muy moderna música de jazz. En 1938 Novo iría más lejos: en un ensayo titulado "Meditaciones sobre el radio" el poeta compara la 
estructura desordenada de la programación radiofónica con el inconsciente freudiano. Según Novo, los ruidos de la radio corresponden al contenido irracional del inconsciente $\mathrm{y}$ por lo tanto la radio es un medio que logra ponernos en contacto con nuestras experiencias más primitivas:

\begin{abstract}
el hombre, originalmente, escuchó y emitió ruidos (y ¿qué otra cosa es la música?); que por su medio percibió el mundo y se comunicó con él. Que inventó después, para su comodidad, las palabras: pero que se conserva el primitivo deseo intacto, de una aptitud de reacción ante ya no la palabra, sino la voz. Para hablar como los freudianos, diríamos que su consciente está lleno de palabras -su yo; mientras que su ello, su subconsciente, está simplemente lleno de ruidos que saben burlar la censura del consciente en instantes de grave emoción. (88)
\end{abstract}

"IU IIIUUU IU" está más cerca del tono travieso de Novo que del moralismo de Duhamel. A Quintanilla le divierte la yuxtaposición de D’Annunzio y la Patagonia, de Gandhi y el fútbol, tanto como a Novo la reunión de "Guadalupe la Chinaca” con la opereta de Massenet. El poema de Quintanilla concluye con una descripción juguetona del revoltijo radial: escuchar un programa de radio, nos dice la voz del narrador que emerge clara y nítida de entre los escombros auditivos, es como salir a pescar en las ondas, ya que nunca sabemos lo que atrapará el radioescucha-pescador: “...y podréis pescar los sonidos que se mecen / en la hamaca kilométrica de las ondas / ...IU IIIUUU IU...”

La relación entre el poema de Quintanilla y el medio radiofónico es compleja; quizá más compleja que la distinción binaria que establece Cœuroy entre textos "radiofónicos” y “radiogénicos”. No se trata de un poema radiogénico, ya que no fue escrito para ser leído en el aire, pero tampoco de un simple ejercicio radiofónico en el que la radio sólo aparece como tema. El poema de Quintanilla es “radiomimético": un texto que reproduce la experiencia de escuchar un aparato de radio a través de procedimientos audio-miméticos: es como si el poeta se hubiera convertido en un aparato de grabación (un artefacto que no existía en los años veinte). Un texto radiofónico se limitaría a usar técnicas literarias tradicionales -metáforas y lenguaje figurado- para describir la audición, pero un texto radiomimético nos presenta una trascripción de todo lo que se oye en la radio, incluyendo "los silbidos y crujidos" de la interferencia. A diferencia de un texto radiofónico, un poema radiomimético como “IU IIIUUU IU”, al ser leído en voz alta con una entonación correcta y efectos vocales suplementarios, reproduciría con gran fidelidad, como si se tratara de una grabación, la transmisión que escuchó el poeta.

La estrategia que emplea Quintanilla en este poema nos recuerda las teorías sobre la “imaginación sin hilos” de Marinetti. El futurista italiano quiso introducir en la poesía y no simplemente describir-el ruido de la modernidad. En su célebre Zang Tumb Tumb, por ejemplo, Marinetii representa un tren a través de los ruidos industriales generados por el ferrocarril: "treno treno treno treno tren tron tron tron [ponte di ferro: tatatluuun-tlin] ssssssiii ssiissii ssiisssssiiii”. Siguiendo una estrategia muy similar, Quintanilla introduce en la poesía los ruidos de un aparato receptor -“IU IIIUUU IU”- para representar la radiofonía. 
El poema de Quintanilla no sólo es radiomimético: también es radiofónico. La primera sección-la trascripción de fragmentos de programas-es un ejercicio radiomimético pero los cuatro últimos versos describen el radio usando una estrategia radiofónica más tradicional: “Todo esto no cuesta ya más que un dólar / Por cien centavos tendréis orejas eléctricas / y podréis pescar los sonidos que se mecen / en la hamaca kilométrica de las ondas”. Estos cuatro versos introducen una voz narrativa que evalúa la secuencia caótica de fragmentos de programas: "Todo esto no cuesta ya más que un dólar”. Las palabras "Todo esto" son un resumen de todos los fragmentos de emisiones que el lector "escucha" en la primera sección; se trata de una traducción de los fragmentos radiomiméticos a un lenguaje radiofónico.

Las palabras “todo esto" no logran captar la complejidad y la riqueza de la programación radial, y este es uno de los mensajes del poema. El poema confronta al lector con dos maneras radicalmente distintas de representar la radio: una estrategia mimética que reproduce la cacofonía y la heterogeneidad del medio y una aproximación radiofónica que ofrece una descripción interpretativa. La sección radiomimética es mucho más compleja -y más cacofónica y heterodoxa- que la conclusión radiofónica, en la que dos palabras apenas, “todo esto”, nos dan una idea de la complejidad de la primera sección.

Una de las críticas que se le ha hecho al estridentismo es que fue un movimiento poético que no llevó a cabo el programa radical que anunció en sus manifiestos (Carlos Monsiváis, por ejemplo, ha escrito que "al no conseguirse interlocutores genuinos, el estridentismo resulta, en lo básico, materia prima de los historiadores de la cultura” [12]). La producción poética del grupo, señala Monsiváis, es bastante tradicional y no logra efectuar la revolución poética que Maples Arce anunció en su manifiesto. "IU IIIUUU IU" demuestra lo contrario: en este poema Quintanilla realiza gran parte del programa poético propuesto en los manifiestos del estridentismo. El poema no sólo celebra la radiofonía -uno de los inventos de la modernidad que el manifiesto propone como modelo poéticosino que lo hace a través de técnicas innovadoras: el poema no está escrito en una métrica tradicional sino en una forma experimental que consiste en el uso de mayúsculas sin signos de puntuación, la utilización de onomatopeyas, y la destrucción de la sintaxis y la gramática. El poema de Quintanilla utiliza varias de las técnicas literarias que Marinetti celebró en su “Manifiesto del futurismo". En “IU IIIUUU IU” no hay puntos ni comas, una ausencia que nos recuerda los esfuerzos de Marinetti por “abolir la puntuación”; y los bloques de texto nos hacen pensar en la forma experimental de textos futuristas como Zang Tumb Tumb. Y si el manifiesto del futurismo incitó a los poetas a evitar adjetivos, Quintanilla escribe el poema sin utilizar un solo adverbio. "IU IIIUUU IU” es uno de los mejores ejemplos de lo que Marinetti llamó “el arte del ruido”.

Hay, sin embargo, una diferencia importante entre el experimento poético de Quintanilla y los textos marinettianos. Para Marinetti, la mejor manera de liberar a la poesía del peso de la tradición era seguir una serie de reglas que incluían el uso de infinitivos y sustantivos y la eliminación de los adjetivos y adverbios. En su poema, Quintanilla propone una estrategia algo distinta: descartar verbos y objetos directos para dejar sólo una cadena de sustantivos. El resultado es una serie de sujetos en busca de verbo que dejan al lector en penumbras: nunca sabremos qué sucedió -o qué está a punto de 
suceder- con las “jazz bands de Virginia y Tenesí” o “los acorazados ingleses”. Este suspenso es otra estrategia radiogénica. Podemos interpretarlo como una referencia poética a uno de los aspectos más curiosos de la radio: muy pocos radioescuchas sintonizan los programas de radio desde su inicio. La gran mayoría llega tarde y sólo logra captar fragmentos descontextualizados. Al igual que el lector de “IU IIIUUU IU”, el radioescucha nunca sabrá que pasó antes de que encendiera su aparato receptor.

La estrategia poética de Quintanilla -el uso de sustantivos descontextualizadosproduce el mismo efecto que los experimentos de Marinetti: crean una serie de imágenes desconcertantes. Marinetti propuso crear sustantivos dobles que sugirieran una relación entre dos palabras sin relación entre sí (como “puerta-grifo” o “plaza-embudo”). Quintanilla crea el mismo tipo de yuxtaposiciones asombrosas, aunque sin unir las palabras con un guion: el plesiosauro diplodocus, por ejemplo, aparece atrapado entre un Lenin severo y un Ghandi pacifista; las “jazz bands” aparecen junto al Popocatépetl. Estos acercamientos nos hacen pensar en la teoría de André Breton sobre las imágenes surrealistas: en su Manifesto del surrealismo, Breton escribió que la poesía surrealista crea chispas y hace cortocircuitos al hacer chocar dos imágenes sin relación entre sí (como en el célebre verso de Lautréamont sobre "el encuentro fortuito de un paraguas y una máquina de coser sobre una mesa de disección” [Breton 328]).

“IU IIIUUU IU” también es un ejemplo de la práctica que Marinetti bautizó con el nombre de "imaginación sin hilos". El lector de este poema se ve obligado a participar activamente en el texto (y en el juego) para descifrar el significado del texto. Marinetti había invitado a los poetas a comunicarse con el lector "sin los cables conductores" de la tradición literaria. Siguiendo esta idea, podemos decir que Quintanilla permite al lector escuchar la radio sin los “cables” de la interpretación. Los textos radiofónicos le dicen al lector cómo interpretar la radio (ya que la descripción es también una interpretación): ya sea de manera negativa (como en el caso de Duhamel) o positiva (como en el caso de Arnheim). El texto de Quintanilla, en cambio, no le impone al lector una visión de la radio sino que lo invita a sacar sus propias conclusiones.

"IU IIIUUU IU” es el más estridentista de todos los poemas estridentistas. Es un poema que desde su título lanza estridencias al aire y hace ruido al imitar el zumbido de las ondas a través de técnicas literarias de vanguardia. Es, también, uno de los pocos poemas que lleva a cabo el proyecto poético presentado en el “Manifiesto” del grupo.

En su Panorama de la radio (1930) el crítico francés André Cœuroy escribió que “quienes aman la radio son, en el fondo, poetas”. Este breve resumen de los proyectos radiales y textuales de los estridentistas nos demuestra cuánta razón tenía Cœuroy al asociar la radio con la poesía, especialmente con la poesía de vanguardia. Más que ningún otro invento moderno, la radio hizo soñar a los poetas de todo el mundo con la imagen de un cielo nocturno cargado de ondas que transportan mensajes invisibles. Además, los poetas reconocieron las muchas semejanzas entre los proyectos vanguardistas y la radiodifusión. Pero en ningún lugar del mundo fue tan fértil y tan prolongado el romance entre los poetas y la radio como en México. En México la radiodifusión nació de la vanguardia ya que fueron los editores y colaboradores de revistas literarias quienes lanzaron los primeros programas al aire. Los estridentistas no sólo escribieron sobre la 
radio: participaron activamente en las primeras estaciones de la capital y se interesaron en las implicaciones culturales del medio.

El amor a la radio distingue a los estridentistas de los otros “ismos” del momento. Es cierto, como han apuntado varios críticos, que el suyo fue un movimiento abortado, una erupción de creatividad que se extinguió abruptamente y no dejó herencia poética en México. A pesar de su breve existencia, los estridentistas fueron el único grupo de vanguardia en el mundo que escribió sobre la radio al mismo tiempo que participó en la radiodifusión. E incluso si el grupo publicó poco -como señala Octavio Paz (17)-, nos dejó “IU IIIUUU IU”, uno de los poemas más originales sobre la experiencia radial y uno de los rarísimos ejemplos de poesía radiomimética. Las palabras de Carlos Noriega Hope no pudieron haber sido más acertadas: "El estridentismo es hermano de leche de la Radiofonía. ¡Son cosas de vanguardia!”

\section{Bibliografía}

Arnheim, Rudolf. Radio. Londres: Faber \& Faber, 1936.

Breton, André. Manifeste du surréalisme. Euvres complètes. París: Gallimard, 1988.

Coeuroy, André. Panorama de la radio. París: Kra, 1930.

Duhamel, Georges. In Defense of Letters [1937]. E. F. Bozman, trad. Nueva York: Graystone Press, 1939.

Gallo, Rubén. "Radiophonism”. Mexican Modernity: the Avant-Garde and the Technological Revolution. Cambridge: MIT Press, 2005. 117-67.

Gálvez, Felipe. "Cincuenta años nos contemplan desde las antenas radiofónicas”. Comunidad 46 (dic. 1973): 733-42.

Gómez de la Serna, Ramón. Greguerías: selección 1910-1960. Madrid: Espasa Calpe, 1991.

Huidobro, Vicente. Tour Eiffel [1918]. Madrid: Ministerio de Cultura, 1989.

Huth, Arno. La radiodiffusion: puissance mondiale. París: Gallimard, 1932.

Kahn, Douglas y Gregory Whitehead, eds. Wireless Imagination: Sound, Radio, and the Avant-garde. Cambridge: MIT Press, 1992.

Larrea Celayeta, Juan. Poesías y poética del ultraísmo. Francisco Fuentes Florido, ed. Barcelona: Mitre, 1984.

Maples Arce, Manuel., “TSH El poema de la radiofonía”. El Universal Ilustrado 308 (5 abr. 1923): 19

“JAZZ = XY VTRS. El jazz en México”. El Universal Ilustrado 373 (3 jul. 1924): 15.

Urbe: super-poema bolchevique en cinco cantos. México: Botas, 1924. Schneider 427-38.

Marinetti, Filippo Tommaso. I manifesti del futurismo. Prima serie. Florencia: Lacerba, 1914.

Scritti Francesi. Milán: Mondadori, 1983.

Teoria e invenzione futurista. Milán: Mondadori, 1996.

Mejía Prieto, Jorge. Historia de la radio y la televisión en México. México: Colmenares, 1972. 
Monsiváis, Carlos. "Dos momentos en la poesía mexicana del siglo XX”. La Gaceta del Fondo de Cultura Económica 391 (jul. 2003): 12-3.

Noriega Hope, Carlos. “Notas del director”. El Universal Ilustrado 308 (5 abr. 1923): 11. Novo, Salvador. "Radioconferencia sobre el radio". Antena 2 (ago. 1924): 10. El Universal Ilustrado 399 (1 ene. 1925): 4-5. Toda la prosa. México: Empresas Editoriales, 1964. 23-25.

“Meditación sobre el radio”. Toda la prosa. México: Empresas Editoriales, 1964. 87-96.

“Radio News, 1938.” La vida en México en el período presidencial de Lázaro Cárdenas. México: CONACULTA, 1994. 166-76.

Paz, Octavio, ed. Poesía en movimiento. México: Siglo XXI, 1966.

Quintanilla, Luis. Radio: poema inalámbrico en trece mensajes. México: Editorial Cultura, 1924.

Salvat Papasseit, Joan. "Poemes en ondes hertzianes”. Poesies. Barcelona: Ariel, 1978.

Schneider, Luis Mario. El estridentismo o una literatura de la estrategia. México: CONACULTA, 1997.

Schwartz, Jorge, ed. Las vanguardias latinoamericanas: textos programáticos y críticos. Madrid: Cátedra, 1991.

Seifert, Jaroslav. Na vlnách TSF. Praga: Nakl. V. Petra, 1925.

Vela, Arqueles. “El hombre antena”. El Universal Ilustrado 308 (5 abr. 1923): 22; 47. Teoría literaria del modernismo. México: Botas, 1949. 